\title{
How Entrepreneurial Management and Continuous Learning Affect the Innovation and Competitiveness of Companies?
}

Received: 02.02.2021

Available online: 29.09.2021

\section{Ketevan Lomineishvili*}

\section{Abstract}

Entrepreneurial management and continuous learning can significantly impact the innovation and competitiveness of companies and improve the performance of a business. Today business faces numerous and complex challenges. Companies require new skills and methods to gain and sustain a competitive advantage. The goal of the research is to understand how entrepreneurial management and continuous learning affect the innovation and competitiveness of companies. We conducted desk research, narrative research to retrieve necessary information and responses to the questions. The study followed a methodology of a narrative review of the literature, articles, and the other sources related to the task by synthesizing concepts. The research findings confirmed our hypothesis - entrepreneurial management and continuous learning are the key determinants for a company's success in today's global marketplace. As organizations, industries, and consumers become more dynamic, effective entrepreneurial management becomes more important. Staying competitive means that organizations need to be innovative, adaptive, and everchanging. An organization's ability to learn is a key strategic capability to compete in modern markets. Driven by disruptive changes, challenges, and technological growth, rapid advances in the field of artificial intelligence are creating a massive shift in terms of proficiencies, the expertise expected in employees. To innovate, to try a new process, or to do something new all requires learning. Lifelong learning plays a key role in helping employees to develop the necessary skills and expertise. Creating a learning culture within the organization is an effective way to improve performance and innovation.

The research findings will be applicable for a broad auditorium interested in the topic and herewith the study results will contribute to future field research in this domain.

Keywords: continuous learning, lifelong learning, constant development, learning organization, organizational commitment, entrepreneurial management, creativity, innovation, competitiveness.

JEL: O31

\footnotetext{
* Faculty of Business Administration, Georgian National University.
} 


\section{Importance of Entrepreneurial}

Management and Continuous

\section{Learning and the impact they make on the Innovation and Competitiveness of companies}

T oday's business environment is dynamic, learning continuously is the only way to sustain a competitive position in the market. Yesterday's organizational knowledge and strategies cannot guarantee tomorrow's success (Senge, 1990). Continuous learning through creativity and entrepreneurial management impacts the companies' innovation and competitiveness. Continuous learning - the process of learning new skills, acquiring new knowledge on an ongoing basis is becoming vital for companies and their employees. People need to acquire new knowledge or skills to see things in a new light and take that next leap. When companies do not support, encourage a continual process of learning, innovation does not happen, processes remain unchanged, and nothing new is ever accomplished, which does not coincide with today's dynamic, rapidly changing environment.

Staying with the familiar may have its dangers, however, in today's fastchanging, dynamic world. An injection of entrepreneurship, by which creative people are encouraged to strike out and come up with new products or services, may become important to the financial health of organizations (Stevenson \& Gumpert, 1985). Entrepreneurship is considered to be the vehicle for economic growth and the development of the country, while innovation is basic, the core of entrepreneurship. Innovation is a cornerstone in this modern and dynamic field. "Every time we create something new, we go from 0 to 1." (Thiel \& Masters, 2014, p.5). These words demonstrate the significance of innovations. Innovations, successful adaptation to the new reality can be achieved when a company chooses constant development and entrepreneurial management. Entrepreneurship is the process by which individuals and organizations pursue opportunities without regard to the resources they currently control (Barringer \& Ireland, 2016). "Entrepreneurship is a universal concept and can be applied in small and medium-sized enterprises (SMEs), large national and multinational organizations, as well as in social ventures, enterprises, communities, and governments" (Hisrich \& Ramadani, 2017, p. 2). Entrepreneurial firms bring new products and services to the market (Barringer \& Ireland, 2016). As for entrepreneurial management, it's the practice of taking entrepreneurial knowledge and utilizing it for increasing the effectiveness of new business venturing as well as smalland medium-sized businesses. To manage entrepreneurially one needs to become an entrepreneurial manager. Hisrich and Ramadani (2017, p. 11) indicate the general functions of managers: Forecaster, Planner, Organizer, Coordinator, Communicator, Facilitator, Motivator, Leader, and Controller; but these functions alone are not sufficient to become an Entrepreneurial Manager. According to Hisrich and Ramadani (2017, p. 11), the entrepreneurial manager, except the above mentioned managerial functions, needs to perform other functions and roles as well: Discoverer, Visionary, Innovative, Creative, Calculated risk-taker, Opportunity seeker, Resource leverage, Self-confident, Drive and intrinsic motivation. "Nothing is certain but death, taxes and the risk in their businesses" (Longenecker et al., 2000); Entrepreneurs should take and manage calculated risks (Hisrich \& Ramadani, 2017). 


\section{Articles}

Continuous learning through creativity is a determiner of the companies' innovation and competitiveness. Establishing a learning culture within the organization is an effective way to improve performance and innovation. If the company wants to increase its competitiveness, it should become a learning organization (George \& Jones, 2014).

The COVID-19 outbreak has had severe economic consequences across the globe. The pandemic has led to dramatic changes in how businesses act, operate and how consumers behave. According to The World Bank of 2020, "COVID-19 is to plunge global economy into worst recession since World War II". COVID-19 forced and still continues to forces company employees to change the way they work almost overnight. To cope with the pandemic crisis companies should start reskilling their workforces now. ("To emerge stronger from the COVID-19 crisis, companies should start reskilling their workforces now"). Herewith cognitive technologies are increasingly being used to solve business problems. Artificial Intelligence, in its broadest sense, will have a fundamental impact on the way that we do business. It will change the way that we make decisions, it will enable completely new business models and approaches to be created and it will allow us to do things that we never before thought possible. (Burgess, 2017, p. 1).

Companies that don't use Artificial Intelligence will soon be obsolete. Artificial intelligence (AI) is going to change our world forever. And the change is likely to be more profound than most people realize today. No matter what job you are in, no matter what business or industry you work in, Al is going to augment, if not completely transform, it. (Marr, 2019, p. 21).
Thus, to survive and sustain, competitiveness businesses need to be focused on life-long learning and improvement.

Continuouslearning, constant development, entrepreneurial management are keys for any enterprise to sustain a competitive advantage, but not always easy to implement changes. Senge (1990) identifies seven types of difficulties, obstacles companies encounter: (I) confusion of identity; (II) avoidance of assuming responsibilities; (III) not facing problems immediately; (IV) analyzing events on a case-by-case basis; (V) nervousness; (VI) lack of information about decisions; (VII) involvement in power relations (Senge, 1990).

After a long time, a decade of research, the authors, researchers have concluded that four biases stand in the way: "We focus too heavily on success, are too quick to act, try too hard to fit in, and rely too much on experts. Each of these biases raises challenges, but each can be curbed with particular strategies." ("Where companies go wrong with learning and development," 2019).

Busy employees attend a training session on "business writing skills", or "conflict resolution", or some other such course with little alignment to their needs. Like lean manufacturing and the lean startup before it, lean learning supports the adaptability that gives organizations a competitive advantage in today's market. It's about learning the core of what you need to learn, applying it to real-world situations immediately, receiving immediate feedback and refining your understanding, and then repeating the cycle. In order to begin practicing lean learning, organizations need to move from measuring credits earned to measuring business outcomes created. Lean learning ensures that employees not only learn the right thing, at the right time, and for the right reasons, but also that they 


\section{Articles}

retain what they learn. ("Where companies go wrong with learning and development," 2019).

The objective of this research paper was to understand how continuous learning and entrepreneurial management affect a company's Innovation and Competitiveness. The paper demonstrates the evolution of this concept over decades and the current conditions.

\section{Methodology}

The present study followed a methodology of a narrative review of the literature, articles, and various important sources related to the research topic. Desk research was conducted, secondary data were collected to highlight the impact of continuous learning and entrepreneurial management on the companies' innovation and competitiveness.

Today the rate of changes is accelerated, artificial intelligence, though till in the very early stages of adoption by most organizations, already impacts a wide range of business functions and our life in general. Covid-19, a global pandemic made tremendous, irreversible changes and many more novelties, new realities are yet to come. The mentioned is a brief reflection of the altered world which requires organizations to be adaptive and proactive. Within the framework of the research, various sources were studied: books related to the topic, scientific papers, articles, etc. The selected methodology helped us to demonstrate new perspectives, highlight new realities, retrieve interesting information and test the hypothesis: entrepreneurial management and continuous learning affect the innovation and competitiveness of companies. The mentioned two variables - entrepreneurial management and continuous learning are the key determinants for a company's success in today's global marketplace.
How Entrepreneurial Management and Continuous Learning Affect the Innovation and Competitiveness of Companies?

The present paper can contribute to future work: to conduct field research and obtain primary data related to the topic entrepreneurial management and continuous learning and their significance for companies.

The selected methodology - narrative review of the literature, articles, and various important sources helped us to confirm the hypothesis: when entrepreneurial management and continuous learning through creativity becomes habitual for the organization it positively impacts on key, vital variables of the company: innovation and competitiveness.

\section{Results}

In a highly competitive and fast-changing economic environment, lifelong learning is becoming increasingly important, essential for both companies and employees. Continuous learning is a way to acquiring knowledge, thorough awareness and deep understanding.

Entrepreneurial orientation is a factor that can improve the performance of a business (Irwin et al., 2018).

Entrepreneurship's importance to an economy and the society in which it resides was expertly articulated in 1934 by Joseph Schumpeter, an Austrian economist, who did the majority of his work at Harvard University. In his book The Theory of Economic Development, Schumpeter argued that entrepreneurs develop new products and technologies that over time make current products and technologies obsolete. Schumpeter called this process creative destruction (Barringer \& Ireland, 2016, p. 22).

Entrepreneurial firms are proactive, innovative, and risk taking (Barringer \& Ireland, 2016). Entrepreneurially managed companies can successfully adopt a new reality.

The present research demonstrated that organizational learning, continuous development and entrepreneurial 


\section{Articles}

management are essential, they play a key role in improving a company's innovative activities, and competitiveness.

Knowledge is the most strategically important intangible resource of any company. Knowledge is one of three key aspects of organizational creativity:

Three key aspects of organizational creativity are (1) knowledge, (2) drive, and (3) ability. Knowledge of the course of action is required for opportunity identification, problem solving, and decision making. Drive refers to the passion, desire, and motivation to do something new and novel with the confidence to proceed as a first mover. Ability refers to the ways in which an individual seeks to identify a solution to a problem by adopting diverse and creative techniques in order to accurately assess and evaluate the situation and identify the best, viable course of action (Hisrich \& Ramadani, 2017, p. 37).

Organizations should make learning a corporate priority. When organizations focus on, dedicate time and resources to developing a learning culture within the organization, they become more competitive. Organizational learning enhances the ability of companies to react quickly to fast-changing market conditions.

Companies must adapt their strategies rapidly in response to competition, be flexible, and adaptable to structural changes brought on by digitization, artificial intelligence. Changes come with knowledge, learning. Experimentation, acquiring new knowledge, creativity, entrepreneurial management are the keys to innovation. Innovation is the cornerstone to competitive advantage and the success of the organizations.

Finally, the present paper results will contribute to future empirical studies, to conducting field research and retrieving primary data about the topic - lifelong learning and its impact on the organizations' success, innovation, entrepreneurial management, and competitiveness in the market.

\section{Discussion}

The objective of the narrative research was to demonstrate the impact of continuous learning and entrepreneurial management on the organizations' performance. The present study provides evidence that continuous learning and entrepreneurial management affect innovation and the competitiveness of organizations. A company should become a learning organization to ensure sustainable development, generate new ideas, use creative approaches, and accelerate growth rate. "A learning organization is an organization skilled at creating, acquiring, and transferring knowledge, and at modifying its behavior to reflect new knowledge and insights" (Senge, 1990, p. 1). To become a learning organization, the company should have a well-defined strategy, "coordinated means by which an organization pursues its goals and objectives" (Carpenter \& Sanders, 2009, p. 34).

Learning organizations are skilled at five main activities: systematic problem solving, experimentation with new approaches, learning from their own experience and past history, learning from the experiences and best practices of others, and transferring knowledge quickly and efficiently throughout the organization (Senge, 1990, p. 3).

The company should actively manage creative and innovative activities in the organizations, taking into consideration the "fundamental distinctions between the two concepts. Creativity is a core building block of innovation. Creative thinking means looking at something in a new way. Creativity is a starting point for innovation. Creativity is about developing ideas, processes, or concepts, 


\section{Articles}

while innovation is the practical application of these" (Hisrich \& Ramadani, 2017, p. 34). For generating new ideas, the company should use various methods: focus groups, brainstorming, brain-writing, library and internet research, forced relationships, bigdream approach, etc. (Hisrich \& Ramadani, 2017). The company should innovate more through experiments. Best managers who run companies entrepreneurially ask questions most. They are extremely curious people (Goodman, 2013). Curiosity is directly related to risk-taking and experimentation.

In most industries, nations, and markets, effective entrepreneurial management challenges existing assumptions and look to generate value in more innovative and creative ways. Effective entrepreneurial management changes the way business is conducted by identifying opportunities and successfully filling them. Since organizations need to renew themselves in order to sustain competitiveness, this can take such forms as championing innovative ideas, providing necessary resources or expertise, or institutionalizing the entrepreneurial activity within the organization's systems and processes (Hisrich \& Ramadani, 2017, p. 2-3).

As Hisrich and Ramadani (2017, p. 11) indicate risk-taking is a primary factor in the entrepreneurial character. "The entrepreneurial process has four distinct phases: (1) identification and evaluation of the opportunity, (2) development of the business plan, (3) determination and evaluation of resource requirements, and (4) implementation and management of the resulting enterprise" (Hisrich \& Ramadani, 2017, p. 12).

Experimentation is a crucial part, a key factor for creativity and innovation. There is no innovation without experimentation. Experimentation is fundamental to getting insights and acquiring new knowledge.
How Entrepreneurial Management and Continuous Learning Affect the Innovation and Competitiveness of Companies?

Experimentation fosters learning by pushing organizations up the hierarchy, from lower to higher stages of knowledge. Experiments bring tangible evidence early in the process, it also reduces the level of uncertainty (see Figure 1 and Figure 2) (Saarelainen, 2018). Hence, in relation with innovation, experimentation can be seen as a search for new value. "Our success at Amazon is a function of how many experiments we do per year, per month, per week, per day" Founder and CEO of Amazon, Jeff Bezos said. (Simmons, 2017).

Experimentation is not guaranteed to be successful, "the knowledge gained from failures is often instrumental in achieving subsequent successes... In the simplest terms, failure is the ultimate teacher" (Maidique \& Zirger, 1985). "A productive failure is one that leads to insight, understanding, and thus an addition to the commonly held wisdom of the organization. An unproductive success occurs when something goes well, but nobody knows how or why" (Nadler, 1989, p.3). To be innovative, a company should build a culture of experimentation. To successfully innovate, organizations need to make experimentation an integral part of everyday operations.

The market is highly competitive nowadays, the companies should differentiate its product so that they operate successfully in the market. The company should learn about its competitors to have competitive intelligence (Barringer \& Ireland, 2016). It must focus on creating unique, new designs, accelerate the new product development process. Organizations should adopt a customization strategy to meet the demands and requirements of individual consumers.

In the era of globalization and integration, it is inevitable and essential for companies to be involved in the constant development process. "Globalization refers to the tendency of firms to extend their sales, ownership, and/ 


\section{Articles}

or manufacturing to new markets abroad" (Dessler, 2013, p. 37). As the company intends to export its product it should consider four types of risk companies face while expanding internationally: Commercial, Currency (Financial), Cross-cultural, and Country risks (Cavusgil et al., 2008).

Staying competitive in today's rapidly changing business environment means that organizations need to be innovative, proactive, and ever-changing. Achieving this depends on the skills and knowledge of the workforce. To innovate, try a new process, create new products, or do something new requires continuous learning.

Lifelong learning plays a key role in helping and supporting employees develop the necessary skills and expertise and acquire new knowledge. Lifelong learning can also lead to greater job satisfaction. More and more companies engage in lifelong learning processes worldwide. The success of the countries' economies significantly depends on companies to be flexible and adaptable to changing environments.

Top managers at large corporations increasingly recognize that continuous learning through creativity is key to remain competitive in today's global economy. "Employees who don't spend at least 5 to 10 hours a week developing new skills will obsolete themselves with the technology," AT\&T former CEO Randall Stephenson said. (Gutierrez, n.d.).

A genuine commitment to lifelong learning and professional development can foster an innovative and creative working environment and is one of the best ways for companies to ensure that they retain their best employees.

Creating a learning culture within the organization is an effective way to improve performance and innovation.
Continuous improvement requires a commitment to learning. How, after all, can an organization improve without first learning something new? Solving a problem, introducing a product, and reengineering a process all require seeing the world in a new light and acting accordingly. In the absence of learning, companies and individuals simply repeat old practices. Change remains cosmetic, and improvements are either fortuitous or shortlived. (Senge, 1990, p. 1).

Organizational learning is a dynamic process. It contains various stages and requires a committed approach:

Organizational learning can usually be traced through three overlapping stages. The first step is cognitive. Members of the organization are exposed to new ideas, expand their knowledge, and begin to think differently. The second step is behavioural. Employees begin to internalize new insights and alter their behaviour. And the third step is performance improvement, with changes in behaviour leading to measurable improvements in results: superior quality, better delivery, increased market share, or other tangible gains. Because cognitive and behavioural changes typically precede improvements in performance, a complete learning audit must include all three (Garvin, 1993).

Three key processes occur in organizational learning: knowledge creation, knowledge retention, knowledge transfer. The organization must ensure that the knowledge gained from this process is retained within the organization and is transferable. ("What is organizational learning and why it's important?"). It is important to create a learning culture within an organization.

Continuous development positively impacts the organization when the acquired knowledge is transferred through the 


\section{Articles}

organization and becomes accessible for the employees. Most important is the knowledge to be used actively by the company staff. "It is very difficult to become knowledgeable in a passive way. Actively experiencing something is considerably more valuable than having it described." For that reason, personnel rotation programs are one of the most powerful methods of transferring knowledge (Schank \& Childers, 1988, p. 9). Education and training programs are powerful tools for transferring knowledge as well. But for maximum effectiveness and usability, they must be linked explicitly to implementation.

\section{Conclusions}

Entrepreneurial management and continuous learning are key determinants for gaining competitive advantage and ensuring long-term sustainability and survival for companies.

Entrepreneurial management makes companies adaptable, flexible, reflective for changes, and proactive in their actions. As today's market is so highly competitive, a business environment characterized with uncertainty and rapidly changing entrepreneurial management becomes essential for companies to achieve success and sustain competitiveness. Entrepreneurial firms' innovations have a significant impact on society.

Entrepreneurial management is closely related to continuous learning, since without constant development managing a company entrepreneurially becomes impossible.

Lifelong learning plays a key role in helping employees to develop the necessary skills and expertise to constantly upgrade their skills. Organizations should stand on a constant development path and more actively find ways to expand internationally, face new challenges, find new perspectives to respond
How Entrepreneurial Management and Continuous Learning Affect the Innovation and Competitiveness of Companies?

to the increased demands of consumers. The organization that continually expands its capabilities, enhances its abilities creates its own future (Senge, 1990). The fundamental activity, operation of an organization is to turn ideas into products, measure how customers respond, and then learn whether to pivot or persevere. All successful organizational processes should be geared to accelerate that feedback loop (Ries, 2017, p. 18). There are many difficulties, obstacles, and challenges in the market but there are opportunities as well, organizations will find their way to significant success and major accomplishments by entrepreneurial management and continuous learning through creativity.

In a rapidly changing and developing business environment if companies want to survive, not to become obsolete, and sustain competitiveness they should turn into knowledge-creating organizations. Organizational learning focuses on the creation of knowledge and the use of that knowledge within the organization. They should focus on continuous learning through creativity and involve in the constant development, lifelong learning process. A genuine commitment to lifelong learning and professional development can support, foster an innovative and creative working environment, positive work setting in the organization, and support the company's long-term success.

\section{Limitations}

The study has certain limitations. It represents the desk research, narrative research - secondary data is collected and analyzed. It's not an empirical study. The paper does not suggest measurement, tools for assessing an organization's rate and level of learning to show the progress. 


\section{Articles}

\section{Future research}

As the present desk research provides narrative review of literature, articles, and various other sources, it makes foundations, contributes to the future field research (both qualitative and quantitative), the empirical studies in this domain. The research findings will be applicable for a broad auditorium, a community interested in the topic as well.

\section{Acknowledgments}

I would like to express heartfelt gratitude towards my friend and manager Associate Professor, Head of the Bachelor's Program in Management at Georgian National University SEU Tengiz Taktakishvili who made a huge contribution to my first scientific article by providing great support and giving professional and fundamental guidance.

\section{References}

Agrawal, S., Smet, A. D., Lacroix, S., \& Reich, A. (2020, May 7). To emerge stronger from the COVID-19 crisis, companies should start reskilling their workforces now. (n.d.). McKinsey \& Company. https://www.mckinsey. com/business-functions/organization/ourinsights/to-emerge-stronger-from-the-covid19-crisis-companies-should-start-reskillingtheir-workforces-now

Barringer, B., \& Ireland, D. (2016). Entrepreneurship: successfully launching new ventures (5th ed.).

Burgess, A. (2017). The executive guide to artificial intelligence: How to identify and implement applications for $A l$ in your organization. Springer.

Carpenter, M. A., \& Sanders, W. G. (2009). Strategic management: A dynamic perspective: Concepts and cases. Prentice Hall.

Cavusgil, Knight, \& Riesenberger. (2008). International business: Strategy, management, and the new realities. Pearson International Edition.

COVID-19 to plunge global economy into worst recession since World War II. (2020, June 8). World Bank. https://www.worldbank.org/en/ news/press-release/2020/06/08/covid-19-toplunge-global-economy-into-worst-recessionsince-world-war-ii

Dessler, G. (2013). Human resource management. Pearson.

Garvin, A. D. (1993). Building a learning organization. Harvard Business Review. https://hbr.org/1993/07/building-a-learningorganization

George, J. M., \& Jones, G. R. (2014). Understanding and managing organizational behavior.

Pearson Higher Ed. Gino, F., \& Staats, B. (2015, November 1). Why organizations don't learn. Harvard Business Review. https://hbr. org/2015/11/why-organizations-dont-learn

Glaveski, S. (2019, October 02). Where companies go wrong with learning and development. Harvard Business Review. https://hbr.org/2019/10/where-companies-gowrong-with-learning-and-development

Goodman, N. (n.d.). Why the best managers ask the most questions? Entrepreneur. https:// www.entrepreneur.com/article/225519

Gutierrez, K. (n.d.). Learning is not a one-time event! Promote continuous learning. https:// www.shiftelearning.com/blog/continuouslearning-workplace

Hisrich, R. D., \& Ramadani, V. (2016). Effective entrepreneurial management: Strategy, planning, risk management, and organization. Springer.

Irwin, K.C., Karen M.L., Joshua R.A., William C.M., Louis D.M., \& Patrick R.G. (2017). "Entrepreneurial Orientation (EO) and human resources outsourcing (HRO): A 'HERO' 


\section{Articles}

combination for SME performance". Journal of Business Research.

Longenecker, G. J., Moore, W. C., \& Petty, J. W. (2000). Small business management: An entrepreneurial emphasis (11th ed.). Cincinnati: South-Western College Publishing.

Maidique, A. M., \& Billie Jo Zirger, B. J. (1985). The New Product Learning Cycle," Research Policy, Vol. 14, No. 6 (1985), pp. 299, 309.

Marr, B. (2019). Artificial intelligence in practice: How 50 successful companies used $A l$ and machine learning to solve problems. John Wiley \& Sons.

Nadler, D. (1989), Even Failures Can Be Productive. New York Times. April 23, 1989, Sec. 3, p. 3.

Ries, E. (2017). The lean startup: How today's entrepreneurs use continuous innovation to create radically successful businesses. Crown Business.

Saarelainen, E. (2018). Why there's no innovation without experimentation. UNHCR Innovation. https://www.unhcr.org/innovation/ why-theres-no-innovation-withoutexperimentation/

Schank, R. C., \& Childers, P. G. (1988). The creative attitude: Learning to ask and answer the right questions. Macmillan Publishing Company.

Senge, P. (1990). The fifth discipline: The art and practice of organizational learning. New York: Doubleday

Simmons, M. (2017). Forget 10,000-Hours: Edison, Bezos and Zuckerberg follow the 10,000-Experiment rule. Observer. https:// observer.com/2017/11/forget-10000-hoursedison-bezos-zuckerberg-follow-the-10000experiment-rule/
How Entrepreneurial Management and Continuous Learning Affect the Innovation and Competitiveness of Companies?

Stevenson, H.H., \& Gumpert, D. E. (1985). The heart of entrepreneurship. Harvard Business Review. https://hbr.org/1985/03/the-heart-ofentrepreneurship C:|Users|Rossy|Downloads| Simmons, M. (2017). Forget 10,000-Hours: Edison, Bezos and Zuckerberg follow the 10,000-Experiment rule. Observer. https:| observer.com|2017\11|forget-10000-hoursedison-bezos-zuckerberg-follow-the-10000experiment-rulel

Thiel, P., \& Masters, B. (2014). Zero to one: Notes on startups, or how to build the future. Currency. What is organizational learning and why it's important? (n.d.). Valamis. https:// www.valamis.com/hub/organizational-learning



Figure 1. Impact of Experimentation

THE EFFECT OF CONTINUOUS LEARNING



Figure 2. 